\title{
The Risk of Securities-based Crowd-funding in China and its Preventive Measures
}

\author{
Ronggang Zhang ${ }^{1}$, Runheng Wang ${ }^{2}$ \\ ${ }^{1}$ School of Business, Northwest University of Politics and Law, Xi'an 710122, China \\ ${ }^{2}$ School of Economics, Northwest University of Politics and Law, Xi'an 710122, China
}

\section{中国股权众筹风险及其防范}

\author{
张荣刚 ${ }^{1}$, 王润街 ${ }^{2}$ \\ 1 西北政法大学商学院, 西安 710122 , 中国 \\ 2 西北政法大学经济学院, 西安 710122 , 中国
}

\begin{abstract}
In recent years, securities-based crowdfunding has been developed rapidly in China. But investors are facing the risk of information asymmetry, law, financial business, operation and information security. This paper sorts the risks by using FAHP, and shows that: the degree of prominence from high to low is information asymmetry risk, law risk, financial business risk, operation risk and information security risk. Therefore, the governor should implement the system of mandatory disclosure of information, make immunity for small public issuing, ensure that the share would be resoled freely and keep circulation channels unobstructed, strengthen the construction of information security system and finally implement the investor protection system, so as to promote securities-based crowdfunding to develop in a healthy way.
\end{abstract}

Keywords: securities-based crowdfunding; FAHP; risk-prevention

\section{摘要}

近年来, 股权众筹发展迅猛, 但对投资 者而言存在信息不对称风险、法律风险、金 融业务风险、操作风险和信息安全风险。采 用模糊综合分析法对其风险进行排序, 实证 结果显示: 突出程度从高到低依次为信息不
对称风险、法律风险、金融业务风险、操作 风险和信息安全风险。因此, 管理当局应当 从实施信息强制披露制度, 实行小额公开发 行豁免, 确保股权份额转售与流通渠道畅通, 加强平台信息安全制度建设, 促进投资者保 护制度落实等方面加强防范, 促进股权众筹 融资健康发展。

关键词: 股权众筹; 模糊层次分析法; 风险 防范

1. 引言

股权众筹是互联网金融的主要模式之一, 也是 “互联网 + ”在金融领域的具体体现 [1] [2]。股权众筹在一定程度上缓解了传统 融资模式的信息不对称、搜寻匹配成本高和 非正规金融的信用缺失问题，使创意项目能 够利用大数据的精准分析在众筹平台上实现 与公众投资者的无缝对接。股权众筹, 2009 年在国外兴起, 2013 年国内第一例股权众筹 案例——美微在淘宝出售股权融资 500 万元, 到 2015 年全年融资金额达到 51.9 亿元, 股 权众筹平台数突破 130 家, 上线项目累计突 破 7500 项，股权众筹得到了迅猛发展。但不 容忽视的是, 股权众筹作为一种私募股权的 新形式, 信用风险和法律风险较传统的私募 股权更大, 同时伴随着操作风险和业务风险 等问题, 风险防控刻不容缓。 
Risk Analysis and Crisis Response in Big Data Era (RAC-16)

目前对股权众筹风险及其防范的研究较 多。邱勋等 ( 2014) 认为股权众筹 (Securities-based Crowdfunding) 存在法 律风险、模式创新风险和道德风险, 应从明 确股权众筹主体监管措拖、采用立体交叉监 管、构建替代性纠纷解决机制、保护投资者 利益和加强投资者教育四个方面进行监管 [3] 孙永祥等（2014）通过对中、美股权众筹平 台的比较分析指出, 我国的股权众筹存在合 法性缺乏、股东人数限制、小股东保护不力, 公司治理机制不够健全等问题 [4]; 龚映清等 （2014）借鉴美国 SEC 众筹新规的内容, 提 出应从强化立法, 规范运行体系, 关注投资 人保护和提升信用体系建设水平四个方面对 股权众筹进行合理监管 [5]; 杨东等 (2014) 分析了股权众筹存在的 7 大风险, 认为处理 风险必须遵循在促进股权众筹稳定发展的前 提下，满足消费者保护最大化的原则 [6]; 周 灿（2015）通过对我国股权众筹平台的法律 和道德风险的梳理, 提出了加快众筹法规体 系建议 [7]。

总体来看, 国内学者对于股权众筹风险 及其防范多是定性分析, 定量分析较少, 也 几乎没有对其风险因素进行排序和实证分析。 本文拟采用模糊综合分析法对股权众筹的风 险因素进行排序和分析, 并针对实证结果提 出相应的风险防范建议。

\section{2. 中国股权众筹的现状与风险揭示}

\section{1 股权众筹的发展历程与现状}

股权众筹最早产生于国外，国内第一家 股权众筹案例是 2013 年美微传媒在淘宝网售 卖股权, 最终实现 1194 个众筹股东, 融资额 达 500 万元。截至 2016 年 3 月底, 国内股权 众筹融资额累计接近 80 亿, 股权众筹平台数 超过 180 家, 范围不断扩大实现了迅猛发展 （详见表 1、图 1)。

表 1 中国股权众筹行业基本情况

\begin{tabular}{cccc}
\hline 年份 & $\begin{array}{c}\text { 累计平 } \\
\text { 台数 } \\
\text { (家) }\end{array}$ & $\begin{array}{c}\text { 实际融资 } \\
\text { 金额 } \\
\text { 元) }\end{array}$ & $\begin{array}{c}\text { 预期融资 } \\
\text { 金额 (亿 } \\
\text { 元) }\end{array}$ \\
\hline $\begin{array}{c}\text { 年 } \\
2015\end{array}$ & 141 & 51.9 & 271.19 \\
\begin{tabular}{c} 
年 \\
\hline
\end{tabular} & 27 & 10.31 & 35.03 \\
\hline
\end{tabular}

数据来源：根据盈灿咨询和众筹之家相关报 告整理, 数据可能存在出入。

从表 1 可以看出, 自 2014 年至 2015 年 末，我国股权众筹平台数从 27 家上升到了 184 家，融资金额从 10.31 亿增长到了 2015 年的 51.9 亿, 实现了 5 倍多的增长。另据资 料显示, 2016 年第一季度新增平台数 41 家, 新增实际融资额 17.6 亿元。但不容忽视的是 实际融资金额与预期融资金额存在较大差距, 尤其是 2015 年仅完成预期融资的 19.1\%，融 资完成率很低。由此可见, 我国股权众筹发 展迅猛, 但期望与落实情况存在显著落差。

\begin{tabular}{|c|c|c|}
\hline \multirow{6}{*}{ 第一梯队人 } & 宗东东家 & 3.45 \\
\hline & 众投邦 & 1. 73 \\
\hline & 蚂蚁达密 & 1. 35 \\
\hline & 爱就投 & 1. 31 \\
\hline & 融e帮疋 & 1. 03 \\
\hline & 北大众筹 & 1. 00 \\
\hline \multirow{7}{*}{ 第二梯乃人 } & 牛投网 & O. 86 \\
\hline & 众投大地 & O. 71 \\
\hline & 创投圈 & 0.70 \\
\hline & 人人投 & 0.68 \\
\hline & 天使客 & O. 55 \\
\hline & 360 淘金 & O. 55 \\
\hline & 36氞 & O. 53 \\
\hline \multirow{7}{*}{ 第三梯乃人 } & 中证创投 & O. 38 \\
\hline & 天使汇 & O. 35 \\
\hline & 天使街 & o. 32 \\
\hline & 爱投社 & O. 31 \\
\hline & 长江众筹 & o. 30 \\
\hline & 宗北众等 & o. 29 \\
\hline & 众等密 & O. 23 \\
\hline
\end{tabular}

图 12016 年第一季度股权众筹平台筹款金额 对比（单位: 亿元)

数据来源: 零壹研究院数据中心, 统计样本 为 55 家主要股权众筹平台交易额

由图 1 可以看出, 2016 年第一季度, 全 国股权众筹平台中，筹资金额达到或超过 1 亿元的有京东东家、众投邦、蚂蚁达客、爱 就投、融 $\mathrm{e}$ 帮和北大众筹等六家, 基本形成 了第一梯队。但不容忽视的是第一梯队平台 的背后都有互联网巨头企业的支持，其余平 台的发展受到了一定程度的限制。



图 2 全国股权众筹平台分布

数据来源: 京北智库 
Risk Analysis and Crisis Response in Big Data Era (RAC-16)

从图 2 中可以看出, 股权众筹平台多集 中于北京、上海、深圳等地, 长三角、珠三 角地区成为股权众筹平台比较集聚的中心。 股权众筹平台的地域差异化发展, 与各地互 联网金融发展程度、社会认知度、配套基础、 投融资环境和创业环境有很大的关系。

总的来说，中国股权众筹从 2013 年起步 到现在，平台数量逐年增加，融资金额不断 上升, 平台分布集中于东部沿海地区。

\section{2 股权众筹运行模式}

股权众筹的运行模式主要分为三类，个 人股东模式、基金股东模式和“领投加跟投” 模式。个人股东模式直接享有公司事项的投 票表决权; 基金股东模式中，投资者实际持 有的是与公司股权等值的基金产品，投资者 对融资项目公司基本上没有影响力; “领投 加跟投” 模式中，领投人作为直接股东参与 公司项目直接管理, 跟投人作为出资方也享 有重大事项的投票权, 但不参与一般性管理 [8]。

\section{4 股权众筹的风险类别及重要性假设}

本文主要从投资者的视角, 以 “领投加 跟投” 模式为核心来探讨股权众筹融资面临 各类风险。

（1）信息不对称风险

信息不对称风险是股权众筹融资面临的 最重要的风险, 主要表现在投资方与融资方 的信息不对称和跟投者与领投者之间的信息 不对称风险，其中前者要比后者破坏力更强。

（2）法律风险

股权众筹融资的第二大风险是法律风险。 主要包含违反企业股东人数限制的风险、违 规公开发行的风险和非法集资的风险，其中 危害最大的是非法集资的风险，其次是违反 公开发行的风险, 最后是违反企业股东人数 限制的风险。

（3）金融业务风险

股权众筹面临的第三大风险是金融业务 风险, 主要包括流动性风险和资金退出风险, 其中后者影响比前者大。

（4）信息安全风险

信息安全风险是投资者面临的风险之一, 主要表现在内部控制风险和技术安全风险,
尤其是内部控制风险，对于股权众筹融资发 展影响力大。

（5）操作风险

操作风险也是股权众筹融资面临的主要 风险之一, 但其重要性相比前四种风险较小。 主要表现在项目经营风险、投资者操作风险 和支付创新风险三个方面，其中项目经营风 险对投资者危害最大，其次是投资者操作风 险, 最后是支付创新风险。

\section{3. 基于模糊层次分析法的中国股权众筹风险 的实证分析}

本文将采用模糊层次分析法对股权众筹 融资风险进行评估，分析信息不对称风险、 法律风险、金融业务风险、信息安全风险和 操作风险对的影响程度并比较, 试图提出防 范股权众筹融资风险的政策建议。

\section{1 评估方法选择依据}

本文认为股权众筹融资风险是难以量化 且结构复杂的, 而模糊层次分析法可以将难 以量化的评价因素通过两两比较加以量化, 将复杂的因素结构化解为一目了然的层次结 构, 同时解决了传统集合理论中的对于边界 不是很清晰事物的定量分析难题, 因此本文 认为模糊层次分析法可以对股权众筹融资风 险进行有效评估 [9] [10]。

\section{2 评估指标体系的建立}

本文所建立的模型采用指标等级评分表 的形式, 根据风险指标权重赋予各指标确定 的分值。根据二级指标对该项指标的影响情 况进行评分, 各二级指标的分值加总即为股 权众筹风险指标的评分分值, 并最终选取 (信 息不对称风险、法律风险、金融业务风险、 信息安全风险、操作风(险) 等五大一级风险指 标体系及 12 个二级指标来构建股权众筹风险 评价指标体系。

\section{3 实证检验}

（1）确定主因素及二级指标 


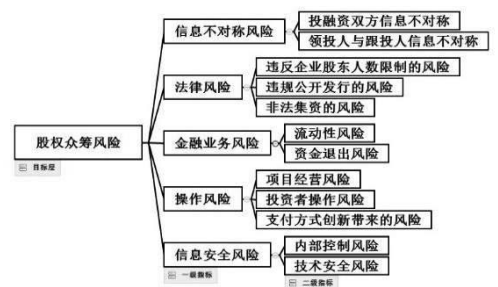

图 3 股权众筹风险评价结构层次图

(2) 建立评价集合, 确定要素评价权重

构造模糊判断矩阵, 确定风险指标因素 的权重。

表 3 1-9 标度法

\begin{tabular}{l|l}
\hline 刻度 & 含义 \\
\hline 1 & $\begin{array}{l}\text { 两个因素相比, 重要 } \\
\text { 性相同 }\end{array}$ \\
\hline 3 & $\begin{array}{l}\text { 两个因素相比, 前者 } \\
\text { 比后者稍重要 }\end{array}$ \\
\hline 5 & $\begin{array}{l}\text { 两个因素相比, 前者 } \\
\text { 比后者明显重要 }\end{array}$ \\
\hline 7 & $\begin{array}{l}\text { 两个因素相比, 前者 } \\
\text { 比后强烈重要 }\end{array}$ \\
\hline 9 & $\begin{array}{l}\text { 两个因素相比, 前者 } \\
\text { 比后者极为重要 }\end{array}$ \\
\hline $2 、 4 、 6 、 8$ & 相邻标准的中间值 \\
\hline \multicolumn{2}{c}{ 综合家意见, 本文采用 $1-9$ 标度法, }
\end{tabular}

综合专家意见, 本文采用 1-9 标度法, 构造判断矩阵, 如下所示

\begin{tabular}{|l|l|l|l|l|l|}
\hline $\mathrm{U}$ & $\mathrm{U}_{1}$ & $\mathrm{U}_{2}$ & $\mathrm{U}_{3}$ & $\mathrm{U}_{4}$ & $\mathrm{U}_{5}$ \\
\hline $\mathrm{U}_{1}$ & 1 & 3 & 5 & 5 & 7 \\
\hline $\mathrm{U}_{2}$ & $1 / 3$ & 1 & 3 & 5 & 5 \\
\hline $\mathrm{U}_{3}$ & $1 / 5$ & $1 / 3$ & 1 & 3 & 5 \\
\hline $\mathrm{U}_{4}$ & $1 / 5$ & $1 / 5$ & $1 / 3$ & 1 & 3 \\
\hline $\mathrm{U}_{5}$ & $1 / 7$ & $1 / 5$ & $1 / 5$ & $1 / 3$ & 1 \\
\hline
\end{tabular}

注：U1-U5 分别代表信息不对称风险、法律 风险、金融业务风险、操作风险、信息安全 风险。

即一级、二级指标判断矩阵为,

$$
\begin{aligned}
A & =\left[\begin{array}{ccccc}
1 & 3 & 5 & 5 & 7 \\
1 / 3 & 1 & 3 & 5 & 5 \\
1 / 5 & 1 / 3 & 1 & 3 & 5 \\
1 / 5 & 1 / 5 & 1 / 3 & 1 & 3 \\
1 / 7 & 1 / 5 & 1 / 5 & 1 / 3 & 1
\end{array}\right] \\
A 3 & =\left[\begin{array}{cc}
1 & 1 / 3 \\
3 & 1
\end{array}\right] A 5=\left[\begin{array}{cc}
1 & 5 \\
1 / 5 & 1
\end{array}\right] A 1=\left[\begin{array}{cr}
1 & 3 \\
1 / 3 & 1
\end{array}\right] \\
A 2 & =\left[\begin{array}{ccc}
1 & 1 / 3 & 1 / 5 \\
3 & 1 & 1 / 3 \\
5 & 3 & 1
\end{array}\right] A 4=\left[\begin{array}{ccc}
1 & 3 & 5 \\
1 / 3 & 1 & 3 \\
1 / 5 & 1 / 3 & 1
\end{array}\right]
\end{aligned}
$$

对于矩阵 $A$, 其最大特征根 $\lambda_{\max }=5.3520$, 最大特征根对应的特征向量为 $\alpha=(0.4872$, $0.2620,0.1384,0.0726,0.0398)$, 即一级 风险指标 $\left\{\mathrm{U}_{1}, \mathrm{U}_{2}, \mathrm{U}_{3}, \mathrm{U}_{4}, \mathrm{U}_{5}\right\}$ 对应的权重分
别是 $0.4872,0.2620,0.1384,0.0726$, 0.0398 。根据相同的计算过程, 可以计算: 矩阵 $A_{1}$ 的最大特征根为 2 , 各因素权重为 $(0.75,0.25)$; 矩阵 $A_{2}$ 的最大特征根为 3.0385 , 各因素权重为 $(0.1047,0.2583$, $0.6370)$; 矩阵 $A_{3}$ 的最大特征根为 2 , 各因素 权重为 $(0.25,0.75)$; 矩阵 $A_{4}$ 的最大特征 根为 3.0385 , 各因素权重为 $(0.6370$, $0.2583,0.1047)$; 矩阵 $A_{5}$ 的最大特征根为 2 , 各因素权重为 $(0.8333,0.1667)$ 。

\section{(3) 一致性检验 \\ $\mathrm{CR}=\mathrm{CI} / \mathrm{RI}, \mathrm{CI}=\frac{\lambda \max -n}{n-1}$}

对于矩阵 $\mathrm{A}$, 其 $\mathrm{CR}=0.079<0.1$, 表明该 判断矩阵通过了一致性检验。同理 $\mathrm{A}_{1}$ 的 $\mathrm{CR}=0<0.1, \mathrm{~A}_{2}$ 的 $\mathrm{CR}=0.03<0.1, \mathrm{~A}_{3}$ 的 $\mathrm{CR}=0<0.1, \mathrm{~A}_{4}$ 的 $\mathrm{CR}=0.03<0.1, \mathrm{~A}_{5}$ 的 $\mathrm{CR}=0<0.1$, 因此判断矩阵都具有满意的一致 性。

\section{(4) 多级模糊分析}

邀请 60 位从事与互联网金融类似工作性 质且且有多久经验的专业人员对单因素风险 等级进行打分 (依次为很高, 高, 中, 低, 很低), 形成一级指标和二级指标的主因素模 糊矩阵:

$$
\begin{aligned}
& \text { R2 }\left[\begin{array}{llllll}
0.5 & 0.25 & 0.2 & 0.05 & 0 & 1
\end{array}\right. \\
& =\left[\begin{array}{ccccc}
0.5 & 0.3 & 0.1 & 0.05 & 0.05 \\
0.45 & 0.4 & 0.1 & 0.05 & 0
\end{array}\right]
\end{aligned}
$$

\begin{tabular}{|c|c|c|c|c|c|}
\hline & rn 4 & 03 & n 1 & ก 15 & 005 \\
\hline & 0.5 & 0.3 & & 0.05 & \\
\hline & 0. & 0 & 0.15 & 0.1 & 0.0 \\
\hline & 0. & & 0. & 0.2 & 0.2 \\
\hline &  & 8 & 0.35 & 0.2 & \\
\hline
\end{tabular}

R3

$R 4=\left[\begin{array}{ccccc}0.35 & 0.25 & 0.2 & 0.15 & 0.05 \\ 0.2 & 0.2 & 0.15 & 0.1 & 0 \\ 0.5 & 0.3 & 0.35 & 0.1 & 0.05 \\ 0.2 & 0.15 & 0 & 0.15\end{array}\right]$

R5

根据模糊综合评判公式 $B_{i}=\alpha_{i} * R_{i}$, 可得 $\mathrm{B}_{1}=(0.4750,0.2625,0.1875,0.0625,0.0125)$ $\mathrm{B}_{2}=(0.4661,0.3154,0.1105,0.0657,0.0476)$ $\mathrm{B}_{3}=(0.3250,0.2375,0.2000,0.1625,0.0750)$ $\mathrm{B}_{4}=(0.4544,0.2258,0.2017,0.0895,0.0286)$ $\mathrm{B}_{5}=(0.3833,0.3083,0.0917,0.1417,0.0750)$ $\mathrm{B}=(0.3529,0.3275,0.1609,0.1087,0.0500)$ 
Risk Analysis and Crisis Response in Big Data Era (RAC-16)

根据最大隶属原则, 可以看出, 最大数 值为 0.3529 , 相应的风险等级为 “很高”。因 此, 股权众筹融资目前所面临的主要风险为信 息不对称风险, 这个结论也印证了专家们的主 观上的判断。此外, 法律风险和金融业务风险 也占有很大比重, 表明这些风险也较为明显。

\section{4 实证结果分析}

\section{（1）一级指标分析}

在本文所设定的五个一级指标里，可以 得出信息不对称风险权重最高, 其次是法律 风险, 再次是金融业务风险, 第四是操作风 险, 最后是信息安全风险。但实证结果与文 中假设不完全相符, 文中假设存在偏差, 需 要调整。

\section{（2）二级指标分析}

投融资参与各方信息不对称风险中尤以 投融资双方信息不对称影响最大, 其次是领 投者和跟投者之间的信息不对称风险，需要 引起高度的关注。

对于法律风险而言, 最为关键的因素是 非法集资的风险，其次是违规公开发行的风 险, 最后是违反股东人数限制的风险

金融业务风险中资金退出风险较为突出, 其次是流动性风险, 检验符合假设。

在操作风险中，项目经营风险占有相对 重要位置, 其次是投资者操作风险和支付方 式创新带来的风险总体处于较风险的状态。 在信息安全风险中内部控制风险最为突 出, 其次是技术安全风险。

总的来说，对股权众筹中所涉及的一级 指标和二级指标进行依次分析, 得到一个概 述性的结果。尽管与文中假设不完全一致, 但仍可以根据这个风险评估结果, 在采取风 险防范措施时, 进行有重点又较全面的宏观 把控。

\section{4. 众筹风险的监管建议}

中国股权众筹融资风险防范和监管应当 是全方位、全天候和体系化的, 同时坚持审 慎监管与鼓励创新相结合的原则, 推进股权 众筹融资健康有序发展。

\section{1 实施信息强制披露制度}

消除股权众筹信息不对称风险的关键就
是信息披露。构建信息强制披露制度, 一是 要求融资方必须披露项目基本情况、筹资用 途和资金使用计划和经营状况，以便投资者 掌握相关信息 [11]; 二是要求领投者和众筹 平台必须进行信息披露, 规范信息发布平台 的运作，满足投资者对于信息披露的要求。 此外, 还应要求领投人加强对项目企业的线 下尽职调查, 以更加全面准确地掌握融资企 业的技术、产品、服务、创意、创始人和创 业精神, 以及股权众筹平台的相关信息等。

\section{2 实行小额公开发行豁免}

从某种程度上讲, 股权众筹构成了证券 公开发行, 但往往并不符合公开发行标准。 考虑到股权众筹的发行人融资数额少但意愿 强烈, 为保障其融资权利和融资机会, 减少 其融资成本，可以借鉴美国《JOBS 法案》 [12] [13] [14] [15], 对其进行小额公开发行 的豁免, 将小额公开发行豁免明确写入相关 法律法规中, 例如在一年内融资金额不超过 500 万元的发行人可免受《证券法》监管; 公开发行标准中股东人数限制条款不完全适 用于股权众筹，而是根据项目金额、项目可 行性、发行方经济条件等信息建立评价体系, 分类划定合规的股东人数区间, 为股权众筹 在中国的发展提供良好的法律环境。

\section{3 确保股权份额转售与流通渠道畅通}

本文认为, 做到股权份额转售与流通渠 道的畅通, 一是要为股权众筹投资者提供专 门的交易场所, 允许 “场内交易”, 提供专属 交易服务 [16] [17]；二是设定股权转让 “冻 结期”, 防范初创企业创始人在股权转让套利 后不再经营该企业, 确保一般投资者退出渠 道的畅通，保护股权众筹投资者的利益。

\section{4 加强平台信息安全制度建设}

首先, 完善平台内部管理, 建立众筹平 台的内部管理体系。完善众筹平台的规章制 度, 优化业务流程, 严格把控信息传递的各 个环节, 填补信息安全漏洞, 防范信息泄露 和篡改; 注重内部培训, 提高平台操作人员 的信息安全意识, 规范操作制度和操作流程, 规避信息安全风险。

其次, 建立专属网络安全技术标准体系, 加大研发支持, 提升网络安全技术水平, 构 


\section{Risk Analysis and Crisis Response in Big Data Era (RAC-16)}

建股权众筹融资网络安全防护体系, 做好股 权众筹融资全流程网络安全的风险监控工作, 努力营造一个安全的网络融资环境。

\section{5 促进投资者保护制度落实}

保障投资者的合法权益、增强投资者信 心的出发点和落脚点是完善的投资者保护制 度。因此, 我们在进行股权众筹运行制度设 计时, 需要将投资者保护作为制度的基本价 值旨向贯穿于制度始终 [18] [19]，审慎监管， 保护投资者利益的同时，促进股权众筹融资 朝着合理、有序、健康的方向发展。

\section{5. 结论}

\section{Acknowledgements}

This study was supported by National Social Science Foundation of China (No. 12XYJ002).

\section{致谢}

本研究得到了国家社会科学基金项目 (12XYJ002) 的资助。

\section{参考文献}

[1] 罗明雄、唐颖、刘勇.互联网金融.中国财 政经济出版社, 北京, 2014 .

[2] 谢平、邹传伟.互联网金融模式研究.中国 人民大学出版社，北京，2014.

[3] 邱勋，陈月波.股权众筹:融资模式、价值 与风险监管.新金融.(9):58-60, 2014.

[4] 孙永祥, 何梦薇, 孔子君, 徐廷玮.我国 股权众筹发展的思考与建议-—从中美 比较的角度.浙江社会科学.(8):146-151, 2014.

[5] 龚映清, 蓝海平.美国 SEC 众筹新规及其 监管启示. 证券市场导报. (9):11-16, 2014.

[6] 杨东, 苏伦嘎. 股权众筹平台的运营模式 及风险防范。国家检察官学院学报. (7):162-168, 2014.

[7] 周灿.我国股权众筹运行风险的法律规制. 财经科学. (3): 14-21, 2015.

[8] 赵尧, 鲁篱.股权众筹领投人的功能解析 与金融脱媒.财经科学. (12):28-31, 2015.

[9] 宋天依，金高莎.基于层次分析法的互联 网金融风险评价及防范对策.金融经济. (16):60-65, 2015.

[10] Dusan Marcek, Lukas Falat, Volatility Forecasting in Financial Risk Management
总体来说, 我国股权众筹融资的发展空 间很广, 发展潜力很大, 但其面临的风险也 十分突出。只有实施信息强制披露制度, 提 高法律制度的适用性, 确保股权份额转售与 流通渠道畅通并加强平台信息安全制度建设, 促进投资者保护制度落实才有可能消弭信息 不对称风险、法律风险、金融业务风险、操 作风险、信息安全风险对股权众筹投资者带 来的冲击, 使更多的投资者加入到股权众筹 的行列中来, 缓解中小企业融资难的问题, 促进科技进步和产业升级转型, 最终推动经 济朝着创新、协调、绿色、开放、共享的方 向发展。

with Statistical Models and ARCH-RBF Neural Networks. Journal of Risk Analysis and Crisis Response, pp.77-95, 2014.

[11] 肖本华.美国众筹融资模式的发展及其对 我国的启示.南方金融. (1):20, 2013.

[12] Ward, and V.Ramach and Ran, Crowdfunding the next hit: Microfunding online experience goods, 2010.

[13] Agrawal A, Catalini C, Goldfarb A. Friends, family, and the flat world: The geography of crowdfunding, NBER Working Paper, 16820, 2011.

[14] Belleflamme P, Lambert T, Schwienbacher A, Crowdfunding: Tapping the right crowd. Journal of Business Venturing, pp. 585-609, 2014.

[15] Mollick, The Dynamics of Crowdfunding: Determinants of Success and Failure, SSRN Scholarly Paper No.ID2088298, Social Science Research Network, Rochester, NY,2012

[16] Read, Crowdfunding: An Empirical and Theoretical Model of Non-Profit Support,2013.

[17] Venkat Kuppuswamy and Barry L.Bayus. Crowdfunding Creative Ideas: The Dynamics of Project Backers in Kickstarter (November 2, 2015). UNC Kenan-Flagler Research Paper No. 2013-15. Available at SSRN: http://ssrn.com/abstract $=2234765$

[18] 傅穹, 杨硕.股权众筹信息披露制度悖论 下的投资者保护路径构建. 社会科学研究. (2):77-82, 2016.

[19]袁康.资本形成、投资者保护与股权众筹 的制度供给-—论我国股权众筹相关制 度设计的路径. 证券市场导报. (12):6, 2014. 